\title{
OPEN Author Correction: Large Enriched Fragment Targeted Sequencing (LEFT-SEQ) Applied to Capture of Wolbachia Genomes
}

\author{
Emilie Lefoulon (D, Natalie Vaisman, Horacio M. Frydman, Luo Sun, Lise Voland, \\ Jeremy M. Foster \& Barton E. Slatko
}

Correction to: Scientific Reports https://doi.org/10.1038/s41598-019-42454-w, published online 11 April 2019

Lise Voland was omitted from the author list in the original version of this Article. This has been corrected in the PDF and HTML versions of the Article, and in the accompanying Supplementary Information file.

The Author Contributions section now reads:

E.L., L.S. and B.E.S. conceived and designed the experiments. E.L. L.V. and N.V. performed the experiments. E.L. analyzed the data. H.F. contributed materials. E.L., J.M.F. and B.E.S. wrote the main manuscript text. All authors reviewed the manuscript.

The Competing Interests section now reads:

E.L., L.S., J.F., L.V. and B.S. are employed by New England Biolabs, Inc., who provided funding for this project.

(c) (i) Open Access This article is licensed under a Creative Commons Attribution 4.0 International License, which permits use, sharing, adaptation, distribution and reproduction in any medium or format, as long as you give appropriate credit to the original author(s) and the source, provide a link to the Creative Commons license, and indicate if changes were made. The images or other third party material in this article are included in the article's Creative Commons license, unless indicated otherwise in a credit line to the material. If material is not included in the article's Creative Commons license and your intended use is not permitted by statutory regulation or exceeds the permitted use, you will need to obtain permission directly from the copyright holder. To view a copy of this license, visit http://creativecommons.org/licenses/by/4.0/.

(c) The Author(s) 2019 